\title{
Training in de urologie anno 2016 en in de toekomst
}

\author{
Barbara M. A. Schout ${ }^{1}$
}

Published online: 15 November 2016

(C) The Author(s) 2016. This article is available at SpringerLink with Open Access.

Samenvatting Training in Urology (http://www.traininginurology.com) bestaat inmiddels tien jaar. In dit artikel delen we onze ervaringen met onderwijs- en curriculumontwikkeling in de urologie.

Trefwoorden training $\cdot$ urologieonderwijs

\section{Training in urology}

Abstract Training in Urology (www.traininginurology. com) now exists for ten years. In this article we share our experiences with het development of education and curricula in urology.

Keywords training $\cdot$ urology education

\section{Introductie}

Het team Training in Urology (TIU) viert dit jaar zijn tienjarig bestaan. Al tien jaar bestaat de unieke formule van een wetenschappelijk team dat bestaat uit urologen, a(n)ios, onderwijs- en patiëntveiligheidsexperts, die samen met de $\mathrm{Ne}$ derlandse Vereniging voor Urologie (NVU) en de diverse onderwijsgremia, alsook met industriële vertegenwoordigers, werken aan ontwikkeling en implementatie van urologisch vaardigheidsonderwijs.

dr. Barbara M. A. Schout

bschout.uro@gmail.com

1 Alrijne ziekenhuis, Leiden/Leiderdorp/Alphen aan den Rijn, Nederland

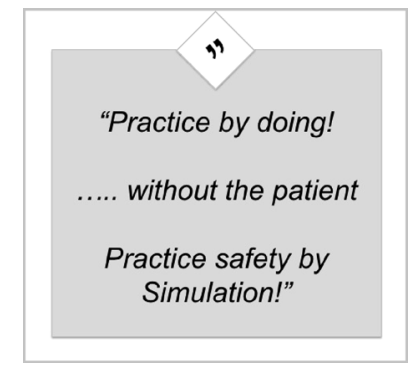

Het gaat binnen TIU dus om onderwijs in brede zin: voor a(n)ios, maar in de toekomst ook steeds meer onderwijs dat is gericht op specialisten zelf. Onder praktische vaardigheden worden uiteraard operatieve ingrepen verstaan. In de toekomst kan de ontwikkeling van onderwijs en wetenschap binnen TIU breder worden en zich ook gaan richten op het uitvoeren van diagnostische procedures, interpretatie van en omgang met radiologie, pathologie of lab, en omgang met het Elektronisch Patiënten Dossier (EPD).

Alle stappen die worden gezet om de kwaliteit van de onderwijsontwikkeling en de medische zorg te verbeteren, worden steeds zo goed mogelijk wetenschappelijk onderbouwd volgens de principes van de evidence based medicine. Alle urologen en aios die hieraan een bijdrage hebben geleverd, zijn wij veel dank verschuldigd. We zijn er trots op dat het urologieonderwijs in Nederland vooruitstrevend is en we hebben er alle vertrouwen in dat dit zo zal blijven. Onze cursussen en projecten zijn reeds meerdere keren ten voorbeeld gesteld door andere specialismen in Nederland en buitenland. 


\section{Hoe ontwikkel je een trainingsprogramma (curriculum)?}

Dat simulatie en trainen buiten de patiënt werkt ... én beter is dan het traditionele meester-gezelmodel staat inmiddels niet meer ter discussie. Ook al blijft het uitdagend en medischethisch lastig onderzoek, de bewijzen zijn er inmiddels: training buiten de patiënt om, maakt het veiliger en beter voor zowel de arts als de patiënt [1-6].

Het is dus niet langer meer de vraag óf we moeten trainen, maar veeleer hoe. Hoe ontwikkel je een zo doelmatig mogelijk trainingsprogramma (curriculum) met een zo hoog mogelijk rendement? Omdat de geneeskunde continu in beweging is en vol zit met innovaties van moderne technieken en middelen, zal hét optimale curriculum een curriculum moeten zijn dat zich ook altijd kan blijven aanpassen.

Een curriculum moet de drie basisvaardigheden bevatten: cognitieve vaardigheden (knowledge), technische (klinische, operatieve) vaardigheden en niet-technische vaardigheden (human factor). In de loop van de jaren heeft TIU de belangrijkste waarden samengevat in een kernfiguur (fig. 1). Men ziet hier een wiel dat altijd rond blijft draaien in een eeuwigdurende cyclus. Wel leidt deze doorgaande cyclus ertoe dat je steeds hoger klimt op de ladder die iemands rol in het onderwijsproces verbeeldt. Iemand die leert, zal voortdurend feedback moeten blijven krijgen. Dit heet ook wel summatieve feedback: men krijgt opbouwende kritiek zonder dat de prestaties meteen langs de meetlat gelegd worden [7].

Het klinkt simpel, maar toch blijft het vaak onderbelicht: bij het opzetten van een trainingsprogramma moet men beginnen met het definiëren van de doelen. De eerste fase is immers Training Needs Analysis; pas daarna komt fase 2, die bestaat uit Training Program Design, en vervolgens fase 3, de Training Media Specification [8-10].

Gedreven door gebrek aan tijd en middelen, of juist door een overdaad aan ijver, gebeurt vaak het omgekeerde en begint men bij fase 3, waarbij het soms zelfs ook blijft. In dat geval gaat er veel geld verloren. Komt het toch van een trainingsprogramma, dan zal in de loop van de tijd duidelijk worden dat de leeropbrengst mogelijk niet zo hoog is als verwacht.

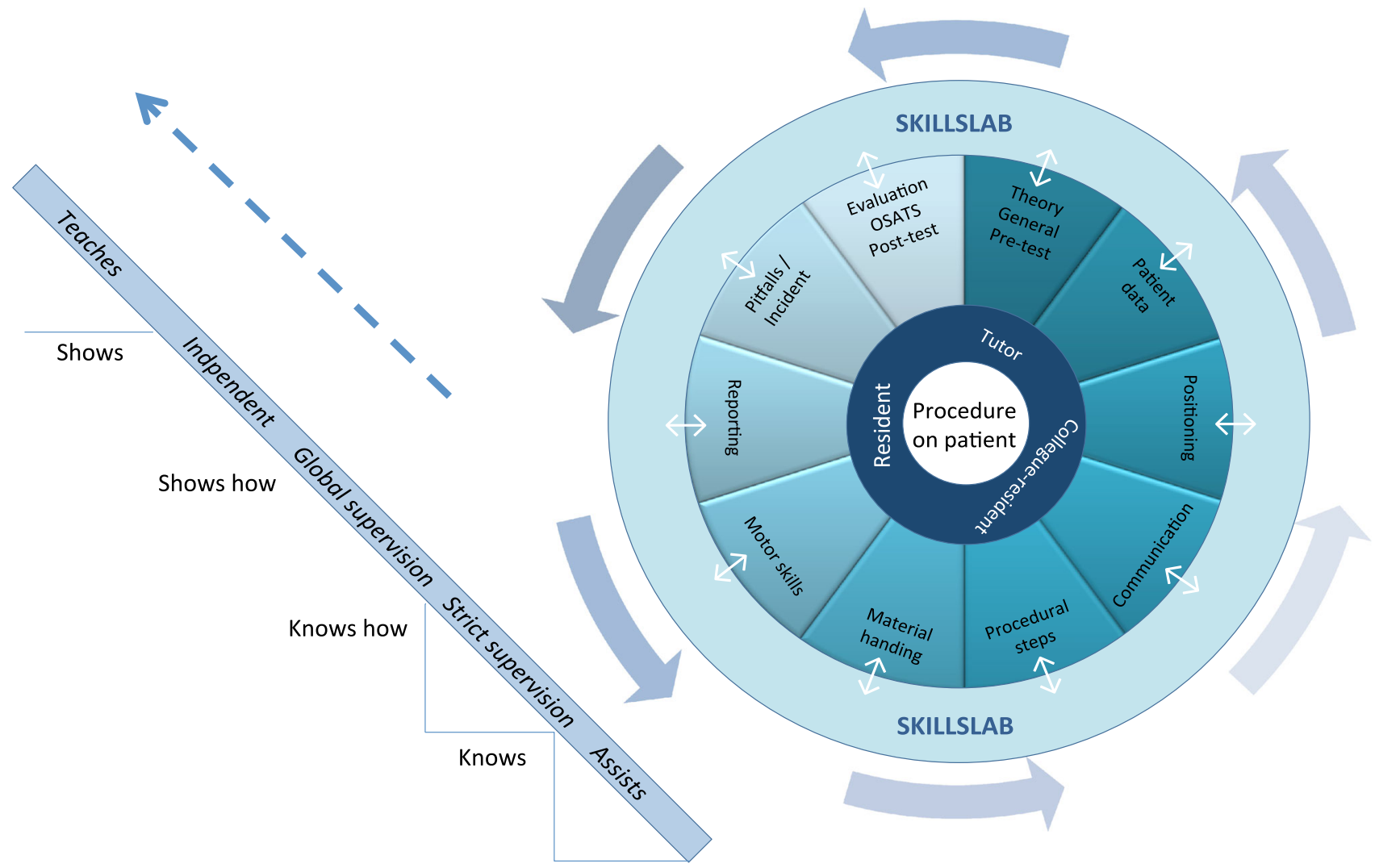

(C) Copyright: Training in Urology

Figuur 1 Kernfiguur Training in Urology met belangrijkste kernwaarden. 


\section{Leerstijlen}

We leren allemaal op onze eigen manier. De één leert graag door eerst te kijken, de ander door meteen te doen. De een onthoudt iets als hij het een keer heeft gelezen, de ander als hij iets heeft gehoord. Maar dat er ook een duidelijk generatieverschil is in hoe we leren, is pas recentelijk onderzocht. Busari en Scheele hebben het generatieverschil mooi in beeld gebracht (tab. 1; [11]). Zij laten zien dat oudere opleiders zich moeten realiseren dat hun pupillen op een andere manier de wereld inkijken dan zij, en dat de kloof tussen verschillende manieren van denken en leren mogelijk groeit met het toenemen van het leeftijdsverschil tussen opleider en pupil. Een opleider die met zijn tijd meegaat en goed aansluit bij zijn aios is echter een mooi rolmodel.

Toetsing is ook een belangrijk onderdeel van een curriculum. Een reden voor toetsing is uiteraard het inzichtelijk en meetbaar maken van de kwaliteiten van degene die het programma volgt, maar een toets blijkt ook zeer motiverend te werken. Dit heet wel formatieve feedback [7]. Heleen de Vries heeft een groot gedeelte van haar promotie gewijd aan de ontwikkeling van valide toetsing en een mooie bruikbare TURT-toets ontwikkeld: de TOCO-TURBT (Test Objective Competence-TURBT). Deze toets is voor en door de Maag Lever Darm Stichting ontwikkeld in het Verenigd Koninkrijk door Barton et al. [12]. Dit examen is landelijk verplicht gesteld voor MDL-artsen alvorens zij coloscopieën mogen verrichten in het kader van bevolkingsonderzoek, om de kwaliteit te waarborgen. Met een team van negen experts werd aansluitend, volgens een Cognitive Training Analysis (CTA) methode, consensus bereikt over alle stappen die een beginnende aios moet kunnen doorlopen, voordat hij op een patiënt mag worden losgelaten (met andere woorden, de droogtraining die in een skillslab of een niet-patiënt gerelateerde setting doorlopen moet worden). Dit overleg heeft bovendien geleid tot criteria waaraan een jonge klare moet voldoen. In fig. 2 is een gedeelte van de test afgebeeld. Naast technische vaardigheden worden met deze test ook niet-technische vaardigheden getoetst, zoals voorbereiding, verslaglegging en communicatie.

Tabel 1 Generatieverschillen in medisch onderwijs [11].

\begin{tabular}{|c|c|c|c|c|}
\hline onderwijskundig element & $\begin{array}{l}\text { grootse generatie } \\
1925-1944\end{array}$ & $\begin{array}{l}\text { babyboomgeneratie } \\
\text { 1945-1964 }\end{array}$ & $\begin{array}{l}\text { generatie X } \\
1965-1984\end{array}$ & $\begin{array}{l}\text { millenniumgeneratie } \\
1985-2005\end{array}$ \\
\hline autoriteit & $\begin{array}{l}\text { - conformistisch } \\
\text { - autoriteiten stellen de } \\
\text { regels } \\
\text { - beveel en heers }\end{array}$ & $\begin{array}{l}\text { - voelen zich meestal on- } \\
\text { gemakkelijk tegenover } \\
\text { autoriteiten } \\
\text { - trekken de legitimiteit } \\
\quad \text { van autoriteit in twijfel }\end{array}$ & $\begin{array}{l}\text { - geen moeite met } \\
\text { autoriteit } \\
\text { - voelen zich niet } \\
\text { geïntimideerd door } \\
\text { autoriteit }\end{array}$ & $\begin{array}{l}\text { - respect moet verdiend } \\
\text { worden } \\
\text { - trekken autoriteit in } \\
\text { twijfel }\end{array}$ \\
\hline tekenen van respect & $\begin{array}{l}\text { - bewondering voor } \\
\text { autoriteit of meerde- } \\
\text { ren } \\
\text { - privileges op basis } \\
\text { van trouwe dienst of } \\
\text { leeftijd }\end{array}$ & $\begin{array}{l}\text { - bewondering voor auto- } \\
\text { riteit, hogergeplaatste } \\
\text { - voorkeur gebaseerd op } \\
\text { sociale status (elite) }\end{array}$ & $\begin{array}{l}\text { - eisen autoriteit } \\
\text { - verwachten waarde- } \\
\text { ring } \\
\text { - verwachten dat er } \\
\text { naar hen geluisterd } \\
\text { wordt op basis van } \\
\text { beroepsmatige of } \\
\text { academische presta- } \\
\text { ties }\end{array}$ & $\begin{array}{l}\text { - eisen autoriteit } \\
\text { - verwachten waardering } \\
\text { - verwachten dat er naar } \\
\text { hen geluisterd wordt op } \\
\text { basis van hun contacten } \\
\text { (volgers) op internet } \\
\text { (Twitter, Facebook) }\end{array}$ \\
\hline kennisbronnen & $\begin{array}{l}\text { - persoonlijke ervaring } \\
\text { - verhalen } \\
\text { - vallen en opstaan }\end{array}$ & $\begin{array}{l}\text { - boeken en bibliotheken } \\
\text { - microfilms } \\
\text { - experts, intellectuelen } \\
\text { - experimenten }\end{array}$ & $\begin{array}{l}\text { - elektronische me- } \\
\text { dia, e-books } \\
\text { - CD-ROM } \\
\text { - online informatie en } \\
\text { databases }\end{array}$ & $\begin{array}{l}\text { - www: Wikipedia, } \\
\text { Google, YouTube, so- } \\
\text { ciale netwerken }\end{array}$ \\
\hline $\begin{array}{l}\text { voorkeur voor onderwijs- } \\
\text { benadering }\end{array}$ & - meester-gezelrelatie & $\begin{array}{l}\text { - lezingen, colleges } \\
\text { - pen en papier } \\
\text { - dia's, overheadsheets }\end{array}$ & $\begin{aligned} \text { - e-mail } \\
\text { - powerpoint- } \\
\quad \text { presentaties }\end{aligned}$ & $\begin{array}{l}\text { - simulaties } \\
\text { - 'serious games' instruc- } \\
\text { ties via YouTube } \\
\text { - virtueel onderwijs via } \\
\text { internet }\end{array}$ \\
\hline reactie op feedback & $\begin{array}{l}\text { - voelen zich makke- } \\
\text { lijk bedreigd door } \\
\text { voortdurende feed- } \\
\text { back }\end{array}$ & $\begin{array}{l}\text { - voelen zich makkelijk } \\
\text { bedreigd door voortdu- } \\
\text { rende feedback }\end{array}$ & $\begin{array}{l}\text { - zijn vertrouwd met } \\
\text { feedback, zijn niet } \\
\text { afhankelijk van } \\
\text { directe en voortdu- } \\
\text { rende feedback }\end{array}$ & $\begin{array}{l}\text { - gedijen uitstekend onder } \\
\text { directe en voortdurende } \\
\text { feedback } \\
\text { - voelen zich onzeker } \\
\text { zonder feedback }\end{array}$ \\
\hline kernwaarde & $\begin{array}{l}\text { - zich gewaardeerd } \\
\text { voelen }\end{array}$ & $\begin{array}{l}\text { - zich gewaardeerd voe- } \\
\text { len }\end{array}$ & $\begin{array}{l}\text { - zich gewaardeerd } \\
\text { voelen }\end{array}$ & - zich gewaardeerd voelen \\
\hline
\end{tabular}




\begin{tabular}{|c|c|c|}
\hline Criteria procedural phase & Score* & Comments \\
\hline \multicolumn{2}{|l|}{ Material related details (sterile) } & \\
\hline Assembles the instruments and connects the tubes correctly and competently & $1|2| 3|4|$ & \\
\hline Adjusts the light settings (1pt), focuses the camera (2pt) and performs white balance (1pt) before the start of procedure & $1|2| 3|4|$ & \\
\hline \multicolumn{2}{|l|}{ Introduction and inspection bladder } & \\
\hline Instilles lubricant into the meatus and (optional) on the final end of the obturator & $\mathrm{Y} / \mathrm{N}$ & \\
\hline Introduces the cystoscope under sight smoothly and safely, while inspecting the complete urethra & $\mathrm{Y} / \mathrm{N}$ & \\
\hline Introduces the obturator blind, smoothly and safely & $\mathrm{Y} / \mathrm{N} \mid \mathrm{N} / \mathrm{A}$ & \\
\hline Inspects the complete bladder using a systematic approach & $1|2| 3|4|$ & \\
\hline Localizes the tumor(s) that have to be resected & $1|2| 3|4|$ & \\
\hline Identifies the left and right ureteral orifice & $\mathrm{Y} / \mathrm{N}$ & \\
\hline Tumor resection & Score* & Comments \\
\hline \multicolumn{2}{|l|}{ Resection tumor(s) } & \\
\hline Applies an adequate strategy in tumor approach (prioritising and systematics) & $1|2| 3|4|$ & \\
\hline Resects the tumor tissue from cranial to caudal & $\mathrm{Y} / \mathrm{N}$ & \\
\hline Resects strokes of adequate depth and length & $1|2| 3 \mid 4$ & \\
\hline Has adequate speed / progression of tumor resection & $1|2| 3|4|$ & \\
\hline Prevents complications adequately & $1|2| 3 \mid 4$ & \\
\hline Handles complications adequately & $1|2| 3 \mid 4$ & \\
\hline Judges end result accurately, including inspection of the complete bladder & $\mathrm{Y} / \mathrm{N}$ & \\
\hline \multicolumn{2}{|l|}{ Continuous variables } & \\
\hline Smoothly changes instruments during procedure & $\mathrm{Y} / \mathrm{N}$ & \\
\hline Continuously maintains orientation in the bladder & $1|2| 3|4|$ & \\
\hline Performs smooth and accurate hemostasis during complete procedure & \begin{tabular}{|l|l|}
$1|2| 3 \mid 4$ \\
\end{tabular} & \\
\hline Applies adequate technique of evacuating tissue chips & \begin{tabular}{|l|l|}
$\mathrm{Y}$ \\
\end{tabular} & \\
\hline Pays close attention to ergonomics & $\mathrm{Y} / \mathrm{N}$ & \\
\hline Reacts adequate on information/messages from the complete operating team and communicates clearly & $\mathrm{Y} / \mathrm{N}$ & \\
\hline
\end{tabular}

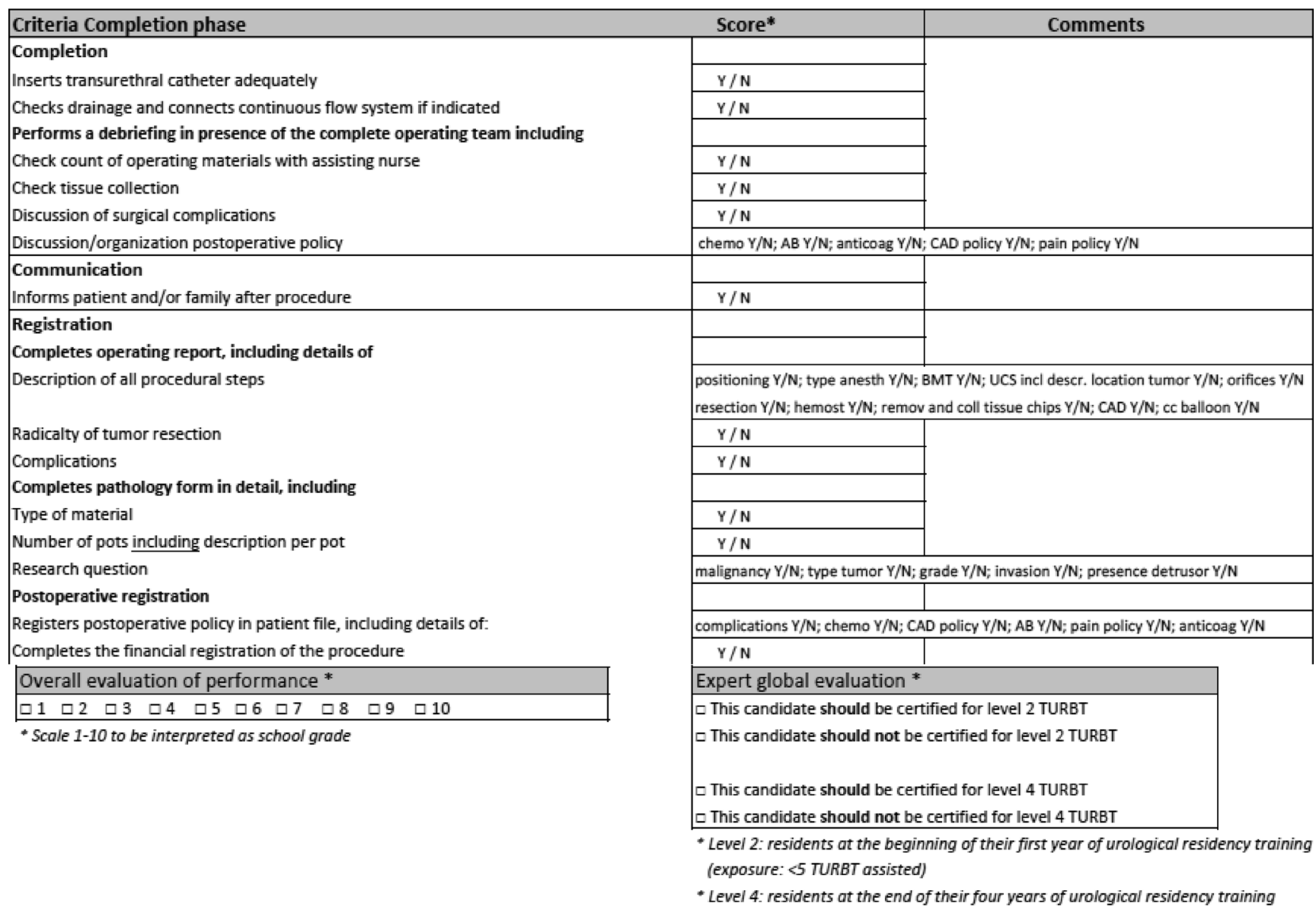

Figuur 2 TOCO-TURT (gedeeltelijk weergegeven) [13]. 


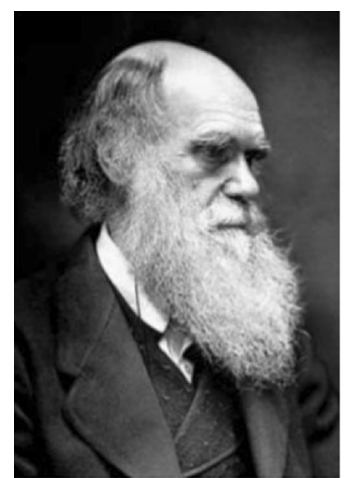

"It is not the strongest of the species that survives, nor the most intelligent that survives.

It is the one that is most adaptable to change."

\section{Charles Darwin}

\section{Tot slot}

In de afgelopen tien jaar is met de totstandkoming van vijf proefschriften 'Training in Urology' en drie ontwikkelde en geïmplementeerde trainingen en toetsen veel ervaring opgebouwd. De urologen, aios, onderwijskundigen, patiëntveiligheidsexperts leren binnen het team veel van elkaar en vullen elkaar aan. Heel graag zouden we de wetenschappelijke lijnen doorzetten in de vorm van een volgende promovenda, die de continuïteit van deze unieke formule zou kunnen waarborgen. Helaas is tot op heden financiële input een bottleneck in het verder kunnen uitrollen van de vele onderzoeksideeën die op dit moment op stapel liggen.

Desondanks blijft TIU niet stilstaan. We zijn actief betrokken bij diverse wetenschappelijke projecten:

- onderzoek naar videoanalyse als valide meetinstrument, samen met het Nederlands instituut voor onderzoek van de gezondheidszorg (NIVEL), met als kartrekker Ad Hendrikx, samen met onder andere Cordula Wagner en Lisanne Verweij;

- onderzoek naar basisrobottrainingen door Willem Brinkman, met als kartrekker onder andere Henk van der Poel;

- ontwikkeling van de training en toets van medische technologie (in eerste instantie gericht op elektrochirurgie en robotchirurgie), waarbij meerdere TIU-leden een rol spelen, samen met het NIVEL op initiatief van het Ministerie van VWS en de Inspectie voor de Gezondheidszorg (IGZ);

- onderzoek naar training en scholing binnen het Elektronisch Patiënten Dossier door anios/onderzoeker Tahnee de Vringer samen met Barbara Schout en Cordula Wagner.

Daarnaast continueren we het toepassen van de vergaarde kennis en kunde doordat TIU-leden zitting hebben in diverse onderwijsgerichte gremia. Zo is Evert Koldewijn bestuurslid van de NVU en betrokken bij het UOI, en tevens voorzitter van de CCO. Ad Hendrikx, Willem Brinkman, Irene Tjiam en Barbara Schout zijn lid van de SWEN. Barbara Schout zit in de Commissie Herziening Curriculum
Urologie (CHCU). Willem Brinkman is actief binnen het bestuur van de Dutch Society of Simulation in Healthcare (DSSH).

We hopen dat alle urologen en aios in Nederland Training in Urology een warm hart blijven toedragen, zoals ze dat tot nu toe altijd hebben gedaan en dat de goed lopende samenwerkingsverbanden zullen blijven bestaan en verder geïntensiveerd kunnen worden.

Open Access This article is distributed under the terms of the Creative Commons Attribution 4.0 International License (http:// creativecommons.org/licenses/by/4.0/), which permits unrestricted use, distribution, and reproduction in any medium, provided you give appropriate credit to the original author(s) and the source, provide a link to the Creative Commons license, and indicate if changes were made.

\section{Literatuur}

1. Barsuk JH, McGaghie WC, Cohen ER, et al. Simulation-based mastery learning reduces complications during central venous catheter insertion in a medical intensive care unit. Crit Care Med. 2009;37(10):2697-701.

2. Cox T, Seymour N, Stefanidis D. Moving the needle: simulation's impact on patient outcomes. Surg Clin North Am. 2015;95(4):827-38.

3. Ahlberg G, Enochsson L, Gallagher AG, et al. Proficiency-based virtual reality training significantly reduces the error rate for residents during their first 10 laparoscopic cholecystectomies. Am J Surg. 2007;193(6):797-804.

4. Dawe SR, Pena GN, Windsor JA, et al. Systematic review of skills transfer after surgical simulation-based training. Br J Surg. 2014;101(9):1063-76.

5. Griswold-Theodorson S, Ponnuru S, Dong C, et al. Beyond the simulation laboratory: a realist synthesis review of clinical outcomes of simulation-based mastery learning. Acad Med. 2015;90(11):1553-60.

6. Schout BM, Ananias HJ, Bemelmans BL, et al. Transfer of cystourethroscopy skills from a virtual-reality simulator to the operating room: a randomized controlled trial. BJU Int. 2010;106(2):226-31.

7. Dornan T, Mann K, Scherpbier AJ, Spencer J. Medical education: theory and practice. London: Churchill Livingstone Elsevier; 2011.

8. Dent JA, Harden RM. A practical guide for medical teachers, 2e druk. Dundee: Elsevier; 2005.

9. Farmer E. et al. Handbook of simulator-based training. Hampshire: Ashgate Publishing Ltd; 1999.

10. Peyton JWR. Teaching and learning in medical practice. Rickmansworth: Manticore Europe Limited; 1998.

11. Busari JO, Scheele F. Differences between generations: relevant for medical education in the Netherlands. Ned Tijdschr Geneeskd. 2015;159:A8900.

12. Barton JR, et al. The validity and reliability of a direct observation of procedural skills assessment tool: assessing colonoscopic skills of senior endoscopists. Gastrointest Endosc. 2012;75:591-7.

13. Vries AH, Muijtjens AMM, Genugten HGJ, et al. Development and validation of the TOCO-TURBT tool: a high-stakes assessment tool that measures surgical competence in transurethral resection of bladder tumour. BJU Int. In druk.

dr. Barbara M.A. Schout uroloog 